\title{
Risk factors for complications after adrenalectomy: results from a comprehensive national database
}

\author{
Lo Hallin Thompson ${ }^{1} \cdot$ Erik Nordenström ${ }^{1} \cdot$ Martin Almquist $^{1} \cdot$ Helene Jacobsson ${ }^{2}$. \\ Anders Bergenfelz ${ }^{1}$
}

Received: 7 July 2016 / Accepted: 14 November 2016/Published online: 28 November 2016

(C) The Author(s) 2016. This article is published with open access at Springerlink.com

\begin{abstract}
Purpose Most knowledge regarding outcome after adrenal surgery stems from retrospective studies reported by highly specialized centres. The aim of this study was to report a national experience of adrenalectomy with particular attention to predictive factors for postoperative complications, conversion from endoscopic to open surgery and length of hospital stay.

Methods Adrenalectomies reported in the Scandinavian Quality Register for Thyroid, Parathyroid and Adrenal Surgery (SQRTPA) 2009-2014 were included. Risk factors for complications, conversion and hospital stay $>3$ days were assessed using univariable and multivariable logistic regression analysis.

Results There were 659 operations. Endoscopic adrenalectomy was performed in $513(77.8 \%)$ operations and almost half of these were robotic assisted. The median length of hospital stay was 3 (range 1-30) days. There was no 30-day mortality. In $43(6.6 \%)$ patients, at least one complication was registered. The only factor associated with complications in multivariable analysis was conversion to open surgery odds ratio (OR) 3.61 (95\% confidence interval 1.07 to 12.12 ). The risk for conversion was associated with tumour size OR 1.03 (1.00 to 1.06)
\end{abstract}

Electronic supplementary material The online version of this article (doi:10.1007/s00423-016-1535-8) contains supplementary material, which is available to authorized users.

Lo Hallin Thompson

lo.hallin-thompson@med.lu.se

1 Department of Surgery, Skåne University Hospital, 22185 Lund, Sweden

2 Research and Development Centre Skåne, Skåne University Hospital, 22185 Lund, Sweden and with malignancy on histopathology OR 8.33 (2.12 to 32.07). Length of hospital stay increased in patients with operation of bilateral tumours OR 3.13, left-sided tumours OR 1.98 , hyper secretion of catecholamines OR 2.32, conversion to open surgery OR 42.05 and open surgery OR 115.18.

Conclusions The present study shows that endoscopic surgery is widely used. Complications were associated with conversion and the risk for conversion was associated with tumour size and malignant tumour. Hospital stay was short.

Keywords Adrenalectomy - Laparoscopic · Complications · Conversion

\section{Introduction}

Adrenalectomies are becoming more frequent worldwide. Contemporary imaging techniques with an increased detection of adrenal incidentalomas and new surgical techniques with reduction of morbidity and mortality with endoscopic methods $[1,2]$ have contributed to the increase in operations. In 1992, Gagner et al. were among the first to describe laparoscopic adrenalectomy [3]. Since then, several studies have evaluated minimally invasive surgery for adrenal lesions, which has become the standard technique for surgical treatment of adrenal tumours $[4,5]$. Previous studies have compared laparoscopic with open adrenalectomy for complications, hospital stay, morbidity and mortality $[2,6,7]$. Laparoscopic adrenalectomy is widely used in both university hospitals and smaller units. Studies have evaluated risk factors for complications associated with surgical technique, surgeon volume and patient-related risk factors. Most of the studies are single-centre studies [8-10], although a few national studies that included specific hospitals or patient groups are available [11-13]. 
Adrenalectomies in Sweden have been registered in the Scandinavian Quality Register for Thyroid, Parathyroid and Adrenal Surgery (SQRTPA) as of 2009. All hospitals that perform adrenal surgery are participating in the registry. The aim of the present study was to evaluate a national experience of adrenal surgery over 6 years and to determine risk factors for complications, conversion from endoscopic to open surgery and prolonged hospital stay.

\section{Material and methods}

\section{Register background}

The SQRTPA was established 2004. In 2009, a module for adrenal surgery was added. The register is an online database and is recognized by the Swedish National Board of Health and Welfare as the national registry within the field.

Patients who underwent adrenal surgery and were reported in the registry 2009-2014 were included in the study. All procedures were performed by endocrine surgeons. Followup was performed at 4-6 weeks postoperatively.

\section{Data variables}

Data were collected for age, gender, body mass index (BMI), hypertension, radiographic tumour size (largest diameter measured on adrenal-CT or MRI), side for adrenal tumour, indication for surgery, surgical technique, histopathology, conversion rate from endoscopic to open surgery, complications (bleeding with transfusion, laceration of viscus, pneumothorax, local infection/abscess and re-operation), postoperative length of stay and 30-day mortality.

Surgical techniques were grouped for the analysis. Endoscopic adrenalectomy included laparoscopic adrenalectomy (posterior and transabdominal) and robotic-assisted laparoscopic adrenalectomy (posterior and transabdominal). Open adrenalectomy included laparotomy, thoracoabdominal approach and open retroperitoneal operations. The technique used was determined by the surgeon on the basis of preoperative findings, availability of equipment and surgical experience.

The primary outcomes were risk factors affecting conversion rate, complication rate and postoperative length of stay (LOS).

The secondary outcomes were variables associated with a surgical technique, laparoscopic, versus robot-assisted adrenalectomy and endoscopic versus open adrenalectomy.

\section{Statistical analysis}

Descriptive statistics are presented as number with valid per cent or median with minimum and maximum values. Binary logistic regression was used to analyse the association between outcome variables and predictors. Analysed outcome variables were complication (defined as bleeding with transfusion, laceration of viscus, pneumothorax, local infection or abscess and re-operation (no or yes)), re-operation (no or yes), conversion (no or yes), postoperative days before discharge (1-3 and 4-30), technique (endoscopic, open) and technique (laparoscopic, robotic). The predictors that were assessed were age, sex, BMI (less than 25 or 25 and higher), adrenal tumour side (right or left or bilateral), largest tumour size, surgical technique (laparoscopic, robotic, open), clinical syndrome of hormonal excess (none, cathecholamines, cortisol and subclinical Cushing syndrome, aldosterone), histopathology (malignant, phaeochromocytoma, other benign lesions) and conversion from endoscopic to open surgery (no or yes). Univariable analyses were conducted, and each outcome variable was assessed with each predictor. Forward multiple linear regression analyses were performed to identify models with significant predictors for each outcome variable, except for re-operation due to small numbers of events. The results from the binary logistic regressions are shown as numbers, odds ratios with $95 \%$ confidence intervals (CI) and $p$ values.

All analyses were conducted using IBM SPSS Statistics 22 for Windows (IBM Corporation, Armonk, NY, USA). We considered $p$ values below 0.05 as statistically significant.

\section{Results}

Some 659 patients underwent adrenalectomy under the 6-year period in ten surgical departments. The distribution between centres is shown in Table 1. Preoperative characteristics of the cohort are summarized in Table 2.

The median age was 59 (range 8-89) years, and 372 (56.4\%) patients were women. Some 215 (32.6\%) patients had hypertension defined as blood pressure $>140 / 90 \mathrm{mmHg}$. On radiological examination, the median size of the tumour was $35 \mathrm{~mm}$ (range 1-200).

Indication for operation could be one or several. The most common indication was a clinical syndrome of hormonal excess; 161 (24.4\%) patients had hormonal excess of aldosterone, $113(17.1 \%)$ patients had hypersecretion of cathecholamines, and $118(17.9 \%)$ patients had hypercortisolism. In 215 (32.6\%) patients, malignancy was suspected on the basis of radiological examination (CT or MRI). Some 32 (4.9\%) patients had preoperatively diagnosed metastases and $75(11.4 \%)$ patients underwent surgery because of a tumour size larger than $40 \mathrm{~mm}$.

Perioperative characteristics are shown in Table 3. Final pathologic diagnosis was, among others, adrenal cortical adenoma in $262(49.6 \%$ ) patients and phaeochromocytoma in 100 (18.9\%) patients. In total, 71 (13.3\%) patients had a diagnosis of malignancy. 
Table 1 Distribution of patients between medical centres

\begin{tabular}{lcccr}
\hline & $n=659(\%)$ & Open & Laparoscopic & Robot \\
\hline \multicolumn{2}{l}{ University hospital } & & & \\
1 & $235(35.7)$ & 8 & 55 & 172 \\
2 & $179(27.2)$ & 30 & 72 & 77 \\
3 & $143(21.7)$ & 33 & 109 & 1 \\
4 & $62(9.4)$ & 16 & 46 & 0 \\
5 & $20(3.0)$ & 4 & 16 & 0 \\
County hospital & & & \\
6 & $12(1.8)$ & 1 & 11 & 0 \\
7 & $4(0.6)$ & 3 & 1 & 0 \\
8 & $2(0.3)$ & 0 & 2 & 0 \\
9 & $1(0.15)$ & 0 & 1 & 0 \\
10 & $1(0.15)$ & 1 & 0 & \\
\hline
\end{tabular}

Valid percent

$n$ number

Endoscopic adrenalectomy was performed in 513 (77.8\%) patients and almost half of these operations were robotically assisted. In total, 146 (22.2\%) patients were operated with open procedures and in 37 (5.6\%) patients, conversion was performed from endoscopic to open surgery.

Some $43(6.5 \%)$ patients had a complication and the most common was bleeding with transfusion. The 30-day mortality rate was nil. Median LOS was 3 (range 1-30) days.

\section{Analysis of primary outcomes}

Univariable and multivariable logistic regression analysis was performed for the primary outcomes. Predictive factors for
Table 3 Results of intra- and postoperative variables for the patients included in the study

\begin{tabular}{|c|c|c|c|}
\hline & & $n=659$ & Percent \\
\hline \multicolumn{4}{|l|}{ Surgical technique } \\
\hline Laparoscopic & & 263 & $(39.9)$ \\
\hline Robotic & & 250 & $(37.9)$ \\
\hline Open & & 146 & $(22.2)$ \\
\hline \multicolumn{4}{|l|}{ Histopathology $(n=528)$} \\
\hline Malignant & & 71 & $(13.4)$ \\
\hline Phaeochromocytoma & & 100 & $(18.9)$ \\
\hline Other benign & & 357 & $(67.6)$ \\
\hline Conversion & & 37 & $(5.6)$ \\
\hline \multicolumn{4}{|l|}{ Complication } \\
\hline Bleeding with transfusion & & 17 & $(2.6)$ \\
\hline Local infection/abscess & & 8 & $(1.2)$ \\
\hline Pneumothorax & & 3 & $(0.5)$ \\
\hline Laceration of viscus & & 5 & $(0.8)$ \\
\hline Re-operation & & 10 & $(1.5)$ \\
\hline 30-day mortality & & 0 & $(0)$ \\
\hline Length of hospital stay (median, days) & $3(1-30)$ & & \\
\hline
\end{tabular}

Valid percent. Median (min-max)

$n$ number

complications, conversion and LOS are presented in Tables 4, 5 and 6, respectively.

Univariable analysis showed that open surgery, large tumour size and conversion to open surgery were associated with an increased risk of complications. However, in the multivariable analysis, conversion from endoscopic to open surgery was the only independent predictive factor for
Table 2 Results of preoperative clinical variables for the patients included in the study

\begin{tabular}{|c|c|c|c|}
\hline & & $n=659$ & Percent \\
\hline Age (median, year) & $59(8-89)$ & & \\
\hline Female & & 372 & $(56.4)$ \\
\hline $\mathrm{BMI} \geq 25$ & & 373 & $(64.1)$ \\
\hline Hypertension & & 215 & $(32.6)$ \\
\hline \multicolumn{4}{|l|}{ Tumour side } \\
\hline Left & & 375 & $(56.9)$ \\
\hline Right & & 254 & $(38.5)$ \\
\hline Bilateral & & 30 & $(4.6)$ \\
\hline Tumour size (median, mm) & $35(1-200)$ & & \\
\hline \multicolumn{4}{|l|}{ Operation indication } \\
\hline Clinical syndrome of hormonal excess & & 399 & $(60.5)$ \\
\hline Suspected malignancy on radiology & & 215 & $(32.6)$ \\
\hline Suspected malignancy on cytology & & 27 & $(4.1)$ \\
\hline Metastasis & & 32 & $(4.9)$ \\
\hline Size only $(\geq 40 \mathrm{~mm})$ & & 75 & $(11.4)$ \\
\hline
\end{tabular}

Valid percent. Median (min-max)

$B M I$ body mass index, $n$ number 
Table 4 Uni- and multivariable regression analysis of risk factors for complication after adrenalectomy

\begin{tabular}{|c|c|c|c|c|c|c|}
\hline & \multicolumn{3}{|c|}{ Univariable logistic regression } & \multicolumn{3}{|c|}{ Multivariable logistic regression } \\
\hline & $n$ & OR $(95 \% \mathrm{CI})$ & $p$ & $n$ & OR $(95 \% \mathrm{CI})$ & $p$ \\
\hline Age & 658 & $1.02(1.00-1.04)$ & 0.109 & & & \\
\hline \multicolumn{7}{|l|}{ Sex } \\
\hline Female & 371 & Ref & & & & \\
\hline Male & 287 & $1.38(0.75-2.53)$ & 0.295 & & & \\
\hline \multicolumn{7}{|l|}{ BMI } \\
\hline$<25$ & 209 & Ref. & & & & \\
\hline$\geq 25$ & 372 & $0.73(0.39-138)$ & 0.336 & & & \\
\hline Tumour side & & & 0.603 & & & \\
\hline Right & 254 & Ref. & & & & \\
\hline Left & 374 & $1.39(0.73-2.64)$ & 0.315 & & & \\
\hline Bilateral & 30 & $0.00(0.00-)$. & 0.998 & & & \\
\hline Largest tumour size & 657 & $1.01(1.01-1.02)$ & $<0.001$ & & & \\
\hline Surgical technique & & & 0.001 & & & 0.112 \\
\hline Laparoscopic & 262 & Ref. & & 212 & Ref. & \\
\hline Robotic & 250 & $0.69(0.30-1.56)$ & 0.368 & 171 & $0.79(0.33-1.92)$ & 0.604 \\
\hline Open & 146 & $2.61(1.29-5.28)$ & 0.007 & 84 & $2.03(0.85-4.84)$ & 0.109 \\
\hline Clinical syndrome of hormonal excess & & & 0.157 & & & \\
\hline None & 260 & Ref. & & & & \\
\hline Cathecholamines & 113 & $0.44(0.16-1.17)$ & 0.098 & & & \\
\hline Cortisol & 117 & $0.42(0.16-1.13)$ & 0.084 & & & \\
\hline Aldosterone & 161 & $0.62(0.29-1.33)$ & 0.222 & & & \\
\hline Histopathology & & & 0.178 & & & \\
\hline Other benign & 357 & Ref. & & & & \\
\hline Malignant & 71 & $1.84(0.79-4.31)$ & 0.157 & & & \\
\hline Phaeochromocytoma & 100 & $0.61(0.2-1.79)$ & 0.364 & & & \\
\hline \multicolumn{7}{|l|}{ Conversion } \\
\hline No & 621 & Ref. & & 449 & Ref. & \\
\hline Yes & 37 & $2.89(1.14-7.34)$ & 0.026 & 18 & $3.61(1.07-12.12)$ & 0.038 \\
\hline
\end{tabular}

Complications that were analysed were bleeding with transfusion, laceration of viscus, pneumothorax, local infection or abscess and re-operation analysed together

$B M I$ body mass index, $O R$ odds ratio, $C I$ confidence interval, Ref. referent

postoperative complications, OR 3.61 (CI 1.07-12.12). Open surgery was also a risk factor when the surgical techniques were grouped as endoscopic versus open technique, OR 2.26 (CI 1.03-4.93), but when the operations were divided into laparoscopic, robotic and open surgery, the significance was lost (Table 4).

The risk for conversion was increased in robotic-assisted surgery, OR 5.14 (CI 1.46-18.11), in the univariable analysis. However, in the multivariable analysis, only tumour size, OR 1.03 (CI 1.00-1.06), and malignant histopathology, OR 8.33 (CI 2.12-32.07), remained predictive (Table 5).

In the multivariable analysis of LOS, tumour on the left side, OR 1.98 (CI 1.14-3.43), bilateral tumours, OR 3.13 (CI 1.08-9.06), open surgery, OR 115.18 (CI 32.94-402.67), excess of cathecholamines, OR 2.32 (CI 1.18-4.59), and conversion to open surgery, OR 42.05 (5.02-352.40), were independent predictive factors for longer hospital stay (Table 6).

\section{Secondary outcomes}

In the univariable analysis of patient characteristics and variables depending on the technique used, older age, large tumour size, malignant histopathology and phaeochromocytoma were positively associated with open surgery when compared with endoscopic surgery. A body mass index of 25 or higher, left-sided tumours, and hypercortisolism or aldosteronism were negatively associated with open surgery. 
Table 5 Uni- and multivariable logistic regression analysis of risk factors for conversion from endoscopic to open surgery

\begin{tabular}{|c|c|c|c|c|c|c|}
\hline & \multicolumn{3}{|c|}{ Univariable logistic regression } & \multicolumn{3}{|c|}{ Multivariable logistic regression } \\
\hline & $n$ & OR $(95 \% \mathrm{CI})$ & $p$ value & $n$ & OR $(95 \% \mathrm{CI})$ & $p$ value \\
\hline Age & 659 & $1.01(0.99-1.04)$ & 0.274 & & & \\
\hline \multicolumn{7}{|l|}{ Sex } \\
\hline Female & 372 & Ref. & & & & \\
\hline Male & 287 & $1.11(0.57-2.16)$ & 0.762 & & & \\
\hline \multicolumn{7}{|l|}{ BMI } \\
\hline$<25$ & 209 & Ref. & & & & \\
\hline$\geq 25$ & 373 & $1.07(0.49-2.34)$ & 0.869 & & & \\
\hline Tumour side & & & 0.387 & & & \\
\hline Right & 254 & Ref. & & & & \\
\hline Left & 375 & $0.62(0.31-1.23)$ & 0.174 & & & \\
\hline Bilateral & 30 & $0.94(0.21-4.25)$ & 0.932 & & & \\
\hline Largest tumour size & 658 & $1.00(0.99-1.01)$ & 0.482 & 383 & $1.03(1.00-1.06)$ & 0.026 \\
\hline \multicolumn{7}{|l|}{ Surgical technique } \\
\hline Laparoscopic & 263 & Ref. & & & & \\
\hline Robotic & 250 & $5.14(1.46-18.11)$ & 0.011 & & & \\
\hline Clinical syndrome of hormonal excess & & & 0.030 & & & \\
\hline None & 260 & Ref. & & & & \\
\hline Cathecholamines & 113 & $0.38(0.13-1.12)$ & 0.079 & & & \\
\hline Cortisol & 118 & $0.65(0.27-1.56)$ & 0.335 & & & \\
\hline Aldosterone & 161 & $0.20(0.06-0.66)$ & 0.009 & & & \\
\hline Histopathology & & & 0.208 & & & 0.005 \\
\hline Other benign & 357 & Ref. & & 291 & Ref. & \\
\hline Malignant & 71 & $2.44(0.9-6.66)$ & 0.081 & 24 & $8.33(2.12-32.07)$ & 0.002 \\
\hline Phaeochromocytoma & 100 & $1.10(0.35-3.46)$ & 0.87 & 68 & $0.67(0.08-5.73)$ & 0.718 \\
\hline
\end{tabular}

$B M I$ body mass index, $O R$ odds ratio, $C I$ confidence interval, Ref. referent

In multivariable logistic regression analysis, larger tumour size OR 1.06 (CI 1.04-1.07) and malignant histopathology OR 11.13 (CI 4.82-25.70) were positive predictive factors for open surgery. (Suppl. Table 1 for the web).

When comparing robotic-assisted and laparoscopic adrenalectomy, older age and larger tumour size were associated with robotic-assisted adrenalectomy in the univariable analysis. In the multivariable logistic regression analysis, older age, OR 1.02 (CI 1.00-1.03), was borderline significant and larger tumour size, OR 1.02 (CI 1.01-1.03), remained the predictive factor for robotic-assisted surgery. (Suppl. Table 2 for the web).

\section{Discussion}

In this national cohort of 659 patients undergoing adrenalectomy, some $5.1 \%$ patients had at least one complication and $1.5 \%$ required re-operation. The only predictive factor associated with complications was conversion from endoscopic to open surgery. In total, $5.6 \%$ of the procedures were converted from endoscopic to open surgery and the risk for conversion was related to larger tumour size and malignant tumours. There were no in-hospital deaths and the 30-day mortality was nil. Factors affecting LOS were left-sided tumour, bilateral tumours, open surgery, excess of cathecholamines and conversion to open surgery.

Laparoscopic adrenalectomy is the standard treatment for adrenal tumours [4]. The technique has a low rate of complications, less postoperative pain, shorter LOS and lower morbidity compared with open surgery [7, 14-16]. Laparoscopic adrenalectomy is therefore cost-effective. There has been an increase in adrenalectomy due to routine imaging and surgical techniques. Benign disease or tumours of unclear significance account for most of the increase [17]. The laparoscopic technique has evolved from transabdominal to posterior endoscopic and robotic-assisted surgery. Current studies recommend open surgery in malignant or large tumours (>100 mm) but some recent studies show equivalent results for laparoscopic surgery regarding morbidity and mortality, providing oncological principles are adhered to [18-21]. In very large or locally invasive tumours, an open surgical approach is recommended to facilitate en bloc excision of the 
Table 6 Uni- and multivariable logistic regression analysis of variables associated with postoperative length of stay

\begin{tabular}{|c|c|c|c|c|c|c|}
\hline & \multicolumn{3}{|c|}{ Univariable logistic regression } & \multicolumn{3}{|c|}{ Multivariable logistic regression } \\
\hline & $n$ & OR $(95 \% \mathrm{CI})$ & $p$ & $n$ & OR $(95 \% \mathrm{CI})$ & $p$ \\
\hline Age & 652 & $1.02(1.01-1.03)$ & 0.003 & & & \\
\hline \multicolumn{7}{|l|}{ Sex } \\
\hline Female & 368 & Ref & & & & \\
\hline Male & 284 & $1.13(0.82-1.55)$ & 0.461 & & & \\
\hline \multicolumn{7}{|l|}{ BMI } \\
\hline$<25$ & 208 & Ref. & & & & \\
\hline$\geq 25$ & 367 & $0.96(0.68-1.35)$ & 0.799 & & & \\
\hline Tumour side & & & 0.299 & & & 0.021 \\
\hline Right & 253 & Ref. & & 177 & Ref. & \\
\hline Left & 370 & $1.06(00.76-1.47)$ & 0.733 & 264 & $1.98(1.14-3.43)$ & 0.016 \\
\hline Bilateral & 29 & $1.84(0.85-3.99)$ & 0.120 & 23 & $3.13(1.08-9.06)$ & 0.035 \\
\hline Largest tumour size & 651 & $1.03(1.03-1.04)$ & $<0.001$ & & & \\
\hline Surgical technique & & & $<0.001$ & & & $<0.001$ \\
\hline Laparoscopic & 261 & Ref. & & 211 & Ref. & \\
\hline Robotic & 250 & $1.72(1.13-2.60)$ & 0.011 & 171 & $1.56(0.95-2.56)$ & 0.081 \\
\hline Open & 141 & $46.51(23.84-90.72)$ & $<0.001$ & 82 & $115.18(32.94-402.67)$ & $<0.001$ \\
\hline Clinical syndrome of hormonal excess & & & $<0.001$ & & & 0.012 \\
\hline None & 255 & Ref. & & 162 & Ref. & \\
\hline Cathecholamines & 113 & $1.03(0.66-1.61)$ & 0.884 & 84 & $2.32(1.18-4.59)$ & 0.015 \\
\hline Cortisol & 116 & $1.06(0.68-1.64)$ & 0.805 & 86 & $1.56(0.77-3.18)$ & 0.219 \\
\hline Aldosterone & 161 & $0.25(0.16-0.41)$ & $<0.001$ & 132 & $0.78(0.40-1.51)$ & 0.458 \\
\hline Histopathology & & & $<0.001$ & & & \\
\hline Other benign & 356 & Ref. & $<0.001$ & & & \\
\hline Malignant & 70 & $5.09(2.94-8.81)$ & 0.006 & & & \\
\hline Phaeochromocytoma & 99 & $1.91(1.21-3.03)$ & & & & \\
\hline \multicolumn{7}{|l|}{ Conversion } \\
\hline No & 617 & Ref. & & 447 & Ref. & \\
\hline Yes & 35 & $14.18(4.94-40.71)$ & $<0.001$ & 17 & $42.05(5.02-352.40)$ & 0.001 \\
\hline
\end{tabular}

Postoperative days before discharge, 1-3 (ref.) versus 4-30

$B M I$ body mass index, $O R$ odds ratio, $C I$ confidence interval, Ref. referent

tumour [22]. It has therefore been recommended that these patients should be treated in specialized centres in order to improve outcomes [23, 24].

There are earlier reports concerning complications in adrenalectomy. Most of them compare outcomes following laparoscopic versus open procedures and most of them are single institution studies from tertiary centres. A lack of standardized definition of complications influences the ability to compare results. Eichhorn-Warry et al. used the Clavien-Dindo classification [25] and found that laparoscopic adrenalectomy decreased the use of intensive care for complications when compared with open procedures [7]. There are only few retrospective, national investigations and none of them included all hospitals that perform adrenalectomies [6, 11-13]. It is therefore interesting that the incidence of reported complications in the literature in general is similar to what was shown in the present study [1, 10, 11, 13, 26, 27]. In the present investigation, conversion to open surgery was the only independent risk factor for complication. Although this could partly be due to bias with larger tumours being at higher risk for conversion, it could be of importance to consider when choosing surgical technique for the individual patient. For some patients, an open approach may be preferred to endoscopic adrenalectomy. The proportion of open procedures in the present report, $22.2 \%$, is comparable with earlier studies [6, 7].

Bergamini et al., showed that age, BMI, tumour size and phaeochromocytoma are risk factors for complications but these in general were lower in referral than in non-referral centres [11]. Surgeon volume influences outcome as well and has been shown by Park et al. [28]. Furthermore, comorbidity has been associated with a risk for complications [1, 13]. These variables were not registered in the database used 
for the present investigation, and therefore, the possible influence of these potential risk factors could not be evaluated.

Considering the well-known effects of hypercortisolism, Cushing's syndrome was expected as a risk factor for impaired wound healing, bleeding and postoperative infection after adrenalectomy. However, this was not shown in the present study. In contrast, Sommerey et al. found that bilateral adrenalectomy for Cushing's disease had more severe complications [29].

The conversion rate in the present study, $5.6 \%$, was consistent with previous reports $[8,10]$. Bittner et al. collected data retrospectively from 402 patients and found that tumour size $>80 \mathrm{~mm}$ was a predictive factor for conversion from endoscopic to open surgery [8]. This is comparable to the present results and indicates that laparoscopic adrenalectomy is used for increasingly larger lesions.

Length of hospital stay is similar in many reports and is shorter after laparoscopic than open procedures [6, 8, 9, 13]. Independent predictive factors for risk for longer hospital stay are not well explored. Of interest is that low surgeon volume and some comorbidities are associated with higher $\operatorname{LOS}[1,28]$. However, these factors were not evaluated in the present study.

Almost half of the endoscopic operations in this cohort, 37.9\% in total, were robotic assisted. Robotic-assisted surgery was used in older patients and more importantly in patients with larger tumours. In the univariable analysis, there was a tendency towards a higher conversion rate compared with the standard laparoscopic technique. However, this association was lost in the multivariable analysis. Several retrospective studies on the use of roboticassisted adrenalectomy have been published during recent years and all reported on small patient groups [30, 31]. In a meta-analysis, some advantages for robotic surgery compared with conventional laparoscopic surgery were shown such as shorter hospital stay, less intraoperative blood loss and lower risk for postoperative complications [32]. However, given the scarce data, these results should be interpreted with caution. The benefits of the robotic technique in subtotal and bilateral adrenalectomy have been discussed in a review article by Nomine-Criqui with equivocal conclusions [33].

Hospital stay is one of the largest costs in health care. Reports regarding costs associated with different surgical techniques are scarce and most have small patient groups [34, 35]. Given the higher cost for robotic surgery compared with standard laparoscopy $[31,36]$, it remains to be proven if the higher number of patients with large tumours that are operated with robotic surgery instead of an open approach could outweigh the increased costs for this new technique.

In the present study, patients with left-sided tumours had a longer hospital stay compared with patients operated for a tumour on the right side. However, the results are not unequivocal. One study found a longer operative time for right-sided tumours subjected to retroperitoneal endoscopic surgery [37]. Other investigations found no differences in outcome but longer operation time [38] and increased risk for surgical complications [10] in patients with left-sided tumours.

There are some limitations to the present study. The study was based on results from a database with predefined data fields, but data was analysed retrospectively. Although the register is designed for the procedure, i.e. adrenalectomy, important variables such as comorbidity, previous abdominal surgery, blood loss and operative time are missing. For nonsurgical complications, for instance pneumonia, venous thrombosis and urinary tract infection, a free text field with ICD coding is available in the database. However, it cannot be ruled out that some of these complications were not coded. Finally, the database does not identify outcomes for the individual surgeon, which may affect the results.

The strength of the present study is that it involved one of the largest national series of patients operated with adrenalectomy. All hospitals that perform adrenal surgery in Sweden participate in the registry and valid data are controlled regularly by an extern audit.

\section{Conclusion}

Within the context of these limitations, the present study shows a low risk for complications, a low conversion rate from endoscopic to open surgery and a short hospital stay for patients undergoing adrenalectomy in Sweden. The study reinforces the benefits of minimal invasive surgery for adrenal tumours on a national level.

Acknowledgements This research was supported by the Skåne Regional Research and Development Fund, Skåne University Hospital Foundation, Skåne University Hospital and Lund University.

The following departments have contributed with patients to the register for this study: Department of Surgery, Sahlgrenska University Hospital, Gothenburg; Department of Surgery, Karlstad Hospital, Karlstad; Department of Surgery, Skåne University Hospital, Lund; Department of Surgery, Karolinska University Hospital, Solna; and Department of Surgery, Uppsala University Hospital, Uppsala.

Author's contributions L. H. T in study conception and design, acquisition of data, analysis and interpretation of data, and drafting of manuscript; E. $\mathrm{N}$ in study conception and design and critical revision of manuscript. M. A in critical revision of manuscript. H. J in analysis and interpretation of data and drafting of part of manuscript (statistical analysis); A. B in study conception and design, analysis and interpretation of data and critical revision of manuscript.

\section{Compliance with ethical standards}

Funding This study was funded by Skåne Regional Research and Development Fund, Skåne University Hospital Foundation, Skåne University Hospital and Lund University.

Conflicts of interest The authors declare that they have no conflict of interest. 
Ethical approval Quality control and analysis of complications were performed according to Swedish legislations for health care providers, and ethical approval was therefore accordingly void.

Informed consent Informed consent was obtained from all individual participants included in the study.

Open Access This article is distributed under the terms of the Creative Commons Attribution 4.0 International License (http:// creativecommons.org/licenses/by/4.0/), which permits unrestricted use, distribution, and reproduction in any medium, provided you give appropriate credit to the original author(s) and the source, provide a link to the Creative Commons license, and indicate if changes were made.

\section{References}

1. Gupta PK et al (2011) Outcomes after laparoscopic adrenalectomy. Surg Endosc 25(3):784-794

2. Barreca $\mathrm{M}$ et al (2003) Expectations and outcomes when moving from open to laparoscopic adrenalectomy: multivariate analysis. World J Surg 27(2):223-228

3. Gagner M, Lacroix A, Bolté E (1992) Laparoscopic adrenalectomy in Cushing's syndrome and pheochromocytoma. N Engl J Med 327(14):1033-1033

4. Smith CD, Weber CJ, Amerson JR (1999) Laparoscopic adrenalectomy: new gold standard. World J Surg 23(4):389-396

5. Jacobs JK, Goldstein RE, Geer RJ (1997) Laparoscopic adrenalectomy. A new standard of care. Ann Surg 225(5):495-501

6. Elfenbein DM et al (2013) Comparison of laparoscopic versus open adrenalectomy: results from American College of SurgeonsNational Surgery Quality Improvement Project. J Surg Res 184(1):216-220

7. Eichhorn-Wharry LI, Talpos GB, Rubinfeld I (2012) American Association of Endocrine Surgeon: laparoscopic versus open adrenalectomy: another look at outcome using the Clavien classification system. Surgery 152:1090-1095

8. Bittner JG et al (2013) Risk factors affecting operative approach, conversion, and morbidity for adrenalectomy: a single-institution series of 402 patients. Surg Endosc 27(7):2342-2350

9. Lachenmayer A et al (2012) Trends in adrenal surgery: institutional review of 528 consecutive adrenalectomies. Langenbecks Arch Surg 397(7):1099-1107

10. Gaujoux $\mathrm{S}$ et al (2011) Risk factors for conversion and complications after unilateral laparoscopic adrenalectomy. Br J Surg 98(10): 1392-1399

11. Bergamini $\mathrm{C}$ et al (2011) Complications in laparoscopic adrenalectomy: the value of experience. Surg Endosc 25(12):3845-3851

12. Villar del Moral JM et al (2011) Original article: adrenal surgery in Spain: final results of a national survey. Cirugía suprarrenal en España: resultados finales de una encuesta nacional (Spanish; Castilian) 89:663-669

13. Murphy MM et al (2010) Trends in adrenalectomy: a recent national review. Surg Endosc 24(10):2518-2526

14. Gagner M et al (1997) Laparoscopic adrenalectomy: lessons learned from 100 consecutive procedures. Ann Surg 226(3):238-246

15. Lee J et al (2008) Open and laparoscopic adrenalectomy: analysis of the National Surgical Quality Improvement Program. J Am Coll Surg 206(5):953-959

16. Imai $\mathrm{T}$ et al (1999) Scientific papers: a case-controlled study of laparoscopic compared with open lateral adrenalectomy. Am J Surg 178:50-53
17. Saunders BD et al (2004) Trends in utilization of adrenalectomy in the United States: have indications changed? World J Surg 28(11): $1169-1175$

18. Miller BS et al (2012) Resection of adrenocortical carcinoma is less complete and local recurrence occurs sooner and more often after laparoscopic adrenalectomy than after open adrenalectomy. Surgery 152(6):1150-1157

19. Mir MC et al (2013) Comparative outcomes of laparoscopic and open adrenalectomy for adrenocortical carcinoma: single, highvolume center experience. Ann Surg Oncol 20(5):1456-1461

20. Donatini $\mathrm{G}$ et al (2014) Long-term survival after adrenalectomy for stage I/II adrenocortical carcinoma (ACC): a retrospective comparative cohort study of laparoscopic versus open approach. Ann Surg Oncol 21(1):284-291

21. Brix D et al (2010) Adrenals: laparoscopic versus open adrenalectomy for adrenocortical carcinoma: surgical and oncologic outcome in 152 patients. Eur Urol 58:609-615

22. Lebastchi AH, Kunstman JW, Carling T (2012) Adrenocortical carcinoma: current therapeutic state-of-the-art. Journal of Oncology:1-11

23. Zini L, Porpiglia F, Fassnacht M (2011) Contemporary management of adrenocortical carcinoma. Eur Urol 60(5):1055-1065

24. Porpiglia F et al (2010) Adrenals: retrospective evaluation of the outcome of open versus laparoscopic adrenalectomy for stage I and II adrenocortical cancer. Eur Urol 57:873-878

25. Dindo D, Demartines N, Clavien P-A (2004) Classification of surgical complications: a new proposal with evaluation in a cohort of 6336 patients and results of a survey. Ann Surg 240(2):205-213

26. Castillo OA et al (2014) Original article: complications associated with laparoscopic adrenalectomy: description and standardized assessment. Descripción y evaluación estandarizada de complicaciones asociadas a adrenalectomía laparoscópica (Spanish; Castilian) 38:445-450

27. Musella M et al (2013) Preoperative workup in the assessment of adrenal incidentalomas: outcome from 282 consecutive laparoscopic adrenalectomies. BMC Surg 13(1): 1

28. Park HS, Roman SA, Sosa JA (2009) Outcomes from 3144 adrenalectomies in the United States: which matters more, surgeon volume or specialty? Arch Surg 144(11):1060-1067

29. Sommerey S et al (2015) Laparoscopic adrenalectomy-10-year experience at a teaching hospital. Langenbecks ArchSurg 400(3):341347

30. Brunaud L et al (2008) Clinical surgery —international: roboticassisted adrenalectomy: what advantages compared to lateral transperitoneal laparoscopic adrenalectomy? Am J Surg 195:433438

31. Winter J et al (2006) Thirty robotic adrenalectomies. Surg Endosc 20(1):119-124

32. Brandao LF et al (2014) Robotic versus laparoscopic adrenalectomy: a systematic review and meta-analysis. Eur Urol 65(6):1154-1161

33. Nomine-Criqui C, et al. 2015 Robotic lateral transabdominal adrenalectomy. J Surg Oncol

34. Ortega $J$ et al (2002) Cost-effectiveness of laparoscopic vs open adrenalectomy: small savings in an expensive process. J Laparoendosc Adv Surg Tech A 12(1):1-5

35. Schreinemakers JMJ, Elias SG, Borel Rinkes IHM (2008) Retroperitoneal endoscopic versus conventional open adrenalectomy: a cost-effectiveness analysis. J Laparoendosc Adv Surg Tech A 18(5):707-712

36. Brunaud L et al (2008) American Association of Endocrine Surgeon: prospective evaluation of 100 robotic-assisted unilateral adrenalectomies. Surgery 144:995-1001

37. Chiang P-H et al (2013) Original article: is right-sided laparoscopic adrenalectomy truly more challenging than left-sided? The 10-year experience of a single institute. Urological Science 24:117-119

38. Rieder JM et al (2010) Differences in left and right laparoscopic adrenalectomy. JSLS 14(3):369-373 